\title{
Infâncias em Educação Infantil
}

\author{
Anete Abramowicz *, Diana Levcovitz ** e Tatiane Cosentino Rodrigues ***
}

Resumo: Este artigo, por sua natureza teórica, trabalha com noçōes tais como infâncias, crianças, multidão e experiência, no intuito de pensar uma educação cujas práticas educativas possibilitem o exercício da infância. $\mathrm{O}$ artigo refaz um caminho no qual a infância e a criança são percebidas "em sua dimensão singular", de modo a recuperar, no fim do percurso, o caráter plural que as noçôes de criança e infância encerram. O referencial teórico parte de Deleuze, Guattari, Agamben, entre outros autores, e busca colocar a infância numa temporalidade múltipla, em detrimento da temporalidade fundada em visões da história e da psicologia, que privilegiam etapas e sucessões cronológicas. Ao afirmarmos a infância como atravessada pela experiência, pela inventividade e pelo desarazoamento, propomos pensar uma educação na direção da multidão.

Palavras-chave: Educação Infantil; infâncias; multidão; experiência; diferença.

\section{Different kinds of childhood in early childhood education}

Abstract: This article, in its theoretical nature, discusses notions such as childhood, children, multitude and experience, in order to consider a kind of early childhood education in which educational routine enables the practice of childhood to happen. The article rebuilds a path on which childhood and children are perceived according to a single particular notion. Towards the ending of the analysis, the plural character involved in the notions of child and childhood is considered. The theoretical framework for the analysis was based on the propositions of Deleuze, Guattari and Agamben, among others. Their views place childhood in a multiple temporality rather than in a single temporality which is determined by historical and psychological perspectives both based on chronological and succession levels. By stating that childhood is crossed by experiences, inventiveness and unreasonableness, our proposal is about thinking of a different kind of education, which leans towards the multitude.

Key words: early childhood education; different kinds of childhood; multitude; experience; difference.

\footnotetext{
* Docente do curso de Pedagogia e do Programa de Pós-Graduação em Educação e Sociologia da Universidade Federal de São Carlos (Ufscar), SP, Brasil. anetabra@ufscar.br

* Psicóloga clínica. Especialista em Educação Infantil pela Universidade Federal de São Carlos (Ufscar).diana.lev@uol.com.br

*** Doutoranda em Educação e mestre em Ciências Sociais pela Universidade Federal de São Carlos (Ufscar).tcrufscar@yahoo.com.br
} 
A potência de viver, a alegria spinozista só escapa à transcendência, à lei mortífera por seu caráter de modalidade fragmentar, polifônica, multirreferencial. A partir do momento em que uma norma pretende unificar a pluralidade dos componentes éticos, a processualidade criativa se oculta.

(Félix Guattari')

Uma educação não fascista concebe a infância como experiência, aceita um currículo pautado no pensamento nômade e vê no espaço-tempo da aula a possibilidade do ato de criação. Pretendemos apontar como a noção de infância, entendida como experiência, pode vir a ser uma potência da vida em contraste, ou mesmo um contraponto ao poder sobre a vida. Apoiamo-nos em autores como Giorgio Agamben (2005), Walter Benjamin (1987), Gilles Deleuze e Félix Guattari (1995) e Michel Foucault (1977; 1999) para a formulação dessa possibilidade teórica.

Entendemos a infância como uma experiência que pode, ou não, atravessar os adultos, da mesma forma que pode, ou não, atravessar as crianças. Nessa perspectiva, a idéia de infância não está vinculada unicamente à faixa etária, à cronologia, a uma etapa psicológica ou a uma temporalidade linear, cumulativa e gradativa, mas ao acontecimento, à arte, ao inusitado, ao intempestivo. Vincula-se, portanto, a uma espécie de des-idade ${ }^{2}$.

A infância, nesse sentido, é aquela que propicia devires, um vir-a-ser, que nada tem a ver com um futuro, com um amanhã ou com uma cronologia temporalmente marcada, mas com aquilo que somos capazes de inventar como experimentação de outras coisas e outros mundos. A infância, em suas experimentações, está associada à criação, trabalha dentro de mais de um regime de tempo, o que está dado, que lhe é dado a conhecer, linear ou circular, com um tempo mais estendido, generoso - um tempo do acontecer e da invenção. Desse modo, defender a idéia de infância como experiência é resistir ao tempo que o poder e o capital impóem ao funcionamento da vida, pois é disso que se trata: o capital gerencia a vida e utiliza estratégias de poder para submeter a todos no interior de uma lógica na qual estamos inseridos e que aboliu as fronteiras, sejam essas globais ou locais, como, por exemplo, trabalho e lazer.

I. Em entrevista a Toni Negri, Cadernos de Subjetividade, 2003.

2. Cf. Abramowicz (2006, p. 321), em que uma das premissas defendidas pela autora é que a escola de Educação Infantil deve promover experiências de infância. 
Primeira cena: Numa sala de aula, uma criança de 5 anos levanta a mão e pede para ir ao banheiro, ou ao bebedouro, ou apontar o lápis, ou...

No átimo entre o pedido e a resposta, há o poder da professora. É mais uma espera humilhante. Nesse tempo, é gerada uma resposta ao pedido, que virá, no mínimo, como redenção ou tortura. O que a criança pede é a permissão para deslocar-se. Ela conhece o espaço da escola, é um sujeito de direitos, não precisa impetrar habeas corpus. Se em grupo, tem que se deslocar em fila.

Os professores da escola para a criança pequena, que constroem e propiciam exercícios de infâncias, trabalham na perspectiva de um determinado cuidar e educar orientado por hábitos de cuidado e educação que se constituem em modos e modelos de agir hegemônicos. Comer de boca fechada, calar nas refeiçôes, banhar-se de determinada forma, pentear e prender o cabelo "desarrumado", por exemplo, são ensinamentos inseridos num determinado modelo hegemônico de produção de hábitos e de condutas, cujo objetivo é a produção de pessoas e indivíduos que se constituam em povo.

Sabemos que a pedagogia tem como função internalizar saberes e "modos de ação", não quaisquer, mas determinados, que de certa forma foram e são "pactuados" entre forças desiguais, que se hegemonizam, subjugam e subjetivam outras a partir de estratégias de saber e de poder. Esse processo de subjetivação faz-se não apenas pela força bruta, como diz Foucault ${ }^{3}$, mas, sim, a partir do que ele denomina de positividade do poder, que não diz apenas não, mas produz corpos, desejos, etc. Ou seja, é o poder sobre a vida - o qual corresponde, na mesma medida, ao poder da vida -, que se efetua como um exercício capilar de produção de "corpos saudáveis", presente no interior de uma lógica que Deleuze denominou de "saúde dominante", a qual, por exemplo, faz lotar as academias de ginástica, produtoras de determinados corpos, às quais as pessoas vão sem que sejam mandadas, nem mesmo obrigadas. O termo Biopolítica, o poder sobre a vida, foi cunhado por Foucault e refere-se à lógica do capital sobrepondo-se ao corpo e à vida. Trata-se do poder que se apropria da vida e a produz. Dessa forma, o corpo é uma realidade biopolítica e, para Foucault, a lógica do biopoder é que ele faz viver e deixa morrer.

\section{Uma única lógica em sala de aula}

A educação esteve embutida no projeto de nação e, desde o século dezoito, veicula uma ordem civilizatória que, quando não ignora, bane, maldiz ou con-

3. FOUCAULT, M. Microfisica do poder. Rio de Janeiro: Graal Editora, 1984, 4ª edição. 
jura a diferença. Naquele projeto, a educação prestou-se à construção do que fosse identitário, mediante, por exemplo, a afirmação de noções sedentárias como povo, raça ou território. Ainda hoje, quando a professora de crianças pequenas solicita, utiliza e ensina determinados modos de ser e agir, ela está aliada a uma determinada concepção de povo e raça, mesmo que não saiba exatamente da processualidade da construção desse conceito e de suas implicações. A professora subjetivada nessa sociedade que produz incessantemente modos de ser e agir acaba internalizando, como algo próprio, hábitos, valores e cuidados que se aliam a uma forma específica de produção do povo.

É no interior dessa lógica que a professora cuida das crianças e as educa para que aprendam as mesmas coisas, num mesmo tempo. A aprendizagem é entendida como cumulativa e linear e recorre a procedimentos de ação supostamente idênticos para crianças diferentes, na medida em que atua e trabalha na perspectiva dessa construção idealizada de igualdade e de povo. A professora, ao mesmo tempo que colabora com a produção da idéia de povo, é por ela construída.

\section{Na contemporaneidade, experimentos em pedagogia não fascista têm sido tentados}

Ao examinar o cotidiano de uma escola pública de educação infantil em Pistóia, na região da Toscana, no norte da Itália, Antonio Gariboldi (2003, p. 44) trouxe-nos o exemplo de uma menina de 4 anos que interrompe seu desenho e aproxima-se da professora para falar-lhe sobre peixinhos, talvez por haver um pequeno tanque de peixinhos na sala. A professora escuta-a e convida outras meninas a participar da conversa. A professora torna possível, então, a amplificação do tema, quando expande a descoberta da aluna para mais crianças. Não é passiva, na medida em que engendra com as crianças novas produções de arte, não se limita à função de vigiá-las e não fica refém da atividade (por extensão, de um currículo). Eis a marca dessa pedagogia, chamada de pedagogia da "escuta", porque respeita mais, prescreve menos e propicia que o encontro se se dê pela arte. Configura-se, assim, um ambiente que, nas palavras do mesmo autor, é "um lugar de vida infantil, muito mais do que um lugar institucional concebido e finalizado para objetivos do tipo didático." (idem, p. 54).

Propor uma educação na perspectiva da diferença implica fugir de uma ordem binária, histórica, que se justifica por contraposiçóes e pela negatividade. Retomar algumas categorias analíticas importantes para a educação, tais como liberdade, trabalho, povo, sociabilidade, raça e tantas outras, obriga-nos a subverter não apenas o pensamento, mas a extrair dele uma nova discursividade, 
algo que não prescreva, nem se assuma "pronto" em definitivo, mas que, ao contrário, abra-se para tantos acontecimentos quantos forem possíveis.

\section{A idéia de multidão que faz tudo vazar}

Para entender a maneira pela qual a educação auxilia na construção de processos civilizatórios, especialmente das crianças pequenas, é necessário que se entenda o que significa colaborar e estar a serviço da construção da idéia de povo, raça e nação. Discutir diferença como prática da educação implica necessariamente construir um conceito que se contraponha ao de povo. Adotamos aqui o conceito de multidão re-elaborado por Michael Hardt e Antonio Negri. ${ }^{4}$ Uma educação "da diferença" deve-se fazer na direção da multidão, e não mais em direção a um povo.

"Povo" e "multidão" remetem ao campo no qual o debate sobre a educação está inserido, já que figuram como conceitos decisivos para a compreensão da política e da esfera pública. Para Virno (2003), a noção de povo prevaleceu à de multidão, cujo conceito se esvaziou e se "perdeu". Não mais se falou em multidão: Hobbes prevaleceu sobre Espinosa. ${ }^{5}$ Sabemos o que significa viver sob a égide da idéia de povo e fazer da educação a base para sua construção. A idéia de povo gera consequiências, como Estado, Estado-Nação, Estado centralizado, território, língua hegemônica, raça, etc. Caminha, portanto, para a produção do uno. A educação que subsidia e contribui para a formação do povo segue a centralidade, a homogeneidade e a adoção de modelos de educação mais apropriados para essa produção.

São inúmeras as produções educacionais que descrevem o cotidiano escolar no qual as crianças negras, gordas, pobres e deficientes sofrem processos de exclusão. A escola inclui a todos, no entanto, de maneira diferenciada. Esse processo excludente aparece, por exemplo, nos indicadores de desempenho escolar que apontam que as crianças negras apresentam desempenhos inferiores às crianças brancas. Vários trabalhos têm detalhado o funcionamento da maquinaria escolar na produção de um povo, indicando processos de subjetivação da escola que pressupõem a necessidade de sentar, calar e copiar para aprender; ou ainda, a valorização de determinado jeito de ser, brincar, falar e pensar. A sociedade disciplinar apontada por Foucault tem na escola seu modelo exemplar, mesmo que em crise, já que também se encontra em meio à passagem

4. Multidão é um livro recente dos autores citados. Destacamos ainda $O$ Império, que foi a primeira obra que os autores trabalharam com a idéia de Multidão, entendida como agente político (Hardt; Negri, O Império, 2005).

5. Ambas as polaridades, povo e multidão, reconhecem como pais putativos a Hobbes e a Espinosa (Virno, Gramática Multidão: para uma análise das formas de vida contemporâneas, 2003). 
para a sociedade de controle, tal como formulada por Deleuze (1992), o que de alguma maneira remete à crise da idéia de povo.

Podemos afirmar que, por exemplo,

o fracasso escolar brasileiro, no âmbito da sociedade disciplinar, aparecia como uma engenharia nacional, como um dispositivo de poder, como uma técnica de dominação política, econômica, de subjetivação das crianças e de produção de um determinado tipo humano e de trabalhador. Este dispositivo reafirmava uma educação pobre para os pobres e, especialmente para os negros, propunha um tipo de aluno dócil, uma escola desejosa de homogeneidade cuja ordem hegemônica se baseava em um tipo ideal de aluno, de estética, de jeito de ser, pensar e aprender onde aqueles que não pertenciam, eram excluídos e/ou reprovados, solicitados a evadir, não prosseguiam. Este dispositivo produtor de determinado aluno tem obviamente uma linha racial a qual implica em uma concepção de povo e uma engenharia eugenista. O bom aluno não era só aquele que aprendia, mas sim aquele que tinha um bom comportamento, Ou seja, o fracasso era associado à desobediência, ao mau comportamento, a ineficácia do aluno em aprender passava pela dificuldade em respeitar as ordens hierárquicas e de poder. (Abramowicz; Rodrigues; Cruz, 2009).

Essa lógica, aos poucos, modifica-se na sociedade atual, cunhada por Deleuze de sociedade de controle. O trabalho é cada vez mais exíguo, sobretudo sob a forma na qual o conhecemos; e produzir trabalhadores na escola, hoje, tem outros significados, entre eles, o de produzir as competências para um trabalho que nunca virá e que deverá ser inventado por cada um. Cada um será o patrão e o escravo de si próprio; dessa forma, inscreve-se, no corpo, o espírito de obrigação que faz com que trabalhemos todo o tempo. O trabalho no neoliberalismo, esse trabalho precarizado após a sociedade disciplinar, passa pelo desemprego e precisa das desigualdades. A escola, ela mesma, é uma empresa que funciona no interior dessa competição, dos desempenhos e da performance, cada uma buscando adequar-se ao "ISO". Passamos da necessidade da produção do aluno obediente, da sociedade disciplinar, para a necessidade da performance ${ }^{7}$, do aluno performático, da sociedade de controle ${ }^{8}$.

6. A Organização Internacional para Padronização (em língua inglesa: "International Standards Organization - ISO", popularmente conhecida como ISO, é uma entidade que atualmente congrega os grêmios de padronização/normalização de 170 países.

7. Conforme definição do dicionário Houaiss - Rubrica: teatro, espetáculo em que o artista atua com inteira liberdade e por conta própria, interpretando papel ou criações de sua própria autoria.

8. DELEUZE, G. Conversações: 1972-1990. Rio de Janeiro: Editora 34, 1998. 
O momento atual sugere a emergência da categoria "multidão" em contraposição à de "povo", que se encontra em crise juntamente com o EstadoNação. Para Hardt e Negri (2001), estaríamos passando da sociedade moderna para a pós-moderna e do imperialismo para o Império. Ele abole todas as fronteiras, "não existe um fora" para o mercado mundial, ele é inclusivo e aproveita toda a forma de diferença. Esse capitalismo contemporâneo, que enaltece as conexôes, a movência e a fluidez, produz novas formas de exploração, novas elites e novas misérias, além da possibilidade do "desligamento" - e, por outro lado, o medo de ser desplugado da rede (Pelbart, 2003). Gera ainda uma lógica que se caracteriza pelo "abocanhar o todo", na qual tudo vai sendo incorporado, exigindo dos intelectuais e dos pesquisadores novas formas de resistência, compreensão e enfrentamentos. O conceito pós-moderno de "multidão" possui um potencial de engajamento e mudança em suas formas plurais, baseadas na diferença e na multiplicidade; por isso, "toda nação precisa fazer da multidão um povo", já que a multidão tudo faz "vazar" (Hardt; Negri, 2005, p. 120), vazar no sentido de que muitas formas de resistência escapam das redes de poder e controle, é a relação entre o poder da vida e o poder sobre a vida.

De acordo com Hardt e Negri, "os conceitos de nação, povo e raça nunca estão muito separados [...] a construção de uma diferença racial absoluta é o terreno essencial para a concepção de uma identidade nacional homogênea." (idem, p. 121). Isso gera, segundo os autores, a constituição da identidade do povo num plano imaginário que exclui toda diferença e corresponde à "subordinação racial e à purificação social". Esse momento pós-moderno, que anuncia a passagem da sociedade disciplinar para a de controle, do imperialismo para o império, da nova forma de poder, cujo objetivo é o poder sobre a vida, da passagem do povo para a multidão, impõe questôes complexas para a educação, as quais - é extremamente necessário encarar e equacionar - ao mesmo tempo em que é preciso aproveitar a crise - a idéia da multidão, já que por ela tudo vaza, para pensar uma educação para a "multidão", e não mais para o povo.

\section{Micropoderes e vida}

No interior dessa lógica, somos subjetivados como uma nação mestiça que vive em uma democracia racial que, se, por um lado, velou a persistência do racismo e da desigualdade racial, ${ }^{9}$ por outro, permitiu a operacionalização, no

9. Carlos Hasenbalg, a partir da década de 1970, analisa a persistência de desigualdades raciais a partir de dados censitários e estudos quantitativos (Hasenbalg, 2005). 
interior do sistema educacional brasileiro, de um discurso racionalista modernizante tributário das teorias raciológicas, nas quais as culturas indígenas e negras, entendidas como inferiores, deveriam ser apagadas. Viabilizou também a substituição do extermínio físico pelo simbólico, sendo a educação um dos principais instrumentos desse processo. É isso que emerge dos índices de exclusão e reprovação escolar que atestam o desempenho escolar inferior das crianças negras, mesmo que apenas entre crianças pobres. É um efeito perverso da maquinaria racista que atua na escola, apesar das falas incessantes das professoras sobre a igualdade de tratamento entre as crianças e da democracia racial brasileira. Atuamos de maneira racista, sustentados por um discurso igualitário e democrático, este é o paradoxo.

Segundo Hardt e Negri (2005), o conceito de nação na Europa desenvolveu-se no terreno do Estado patrimonial e absolutista. A nação sucedeu a ordem feudal do súdito para a ordem disciplinar do cidadão. $\mathrm{O}$ conceito de nação supõe, então, uma "vontade geral" - para os autores, uma "identidade do povo" - transformada em algo quase "natural e original". A identidade do povo é, de tal sorte, uma laboriosa e complexa construção na qual a escola vem desempenhando um papel não desprezível. A base da pedagogia assenta-se na idéia da produção desse povo, construída para as crianças, desde as menores até os jovens e os adultos. A pedagogia centrada nos currículos nacionais unificados tem feito sua parte na construção desse povo, exigindo uma língua única e uma gramaticalidade; na valorização de uma determinada estética e padrões homogêneos; e na adoção de idéias comuns, entre elas, à luz da experiência brasileira, a da democracia racial.

Sabemos que a sociedade moderna oferece várias usinas para a fabricação da subjetividade, cada uma com sua singularidade: escola, família, trabalho, lazer. Mas o que está posto para a subjetividade na sociedade de controle que pretende abolir o fora e o dentro? Quando estamos em casa com o nosso computador, estamos fora ou dentro do trabalho? Quando atendemos ao telefone celular, estamos no fora ou no dentro? É nesse sentido que Deleuze afirma que a sociedade de controle aboliu fronteiras, mas não abriu mão do controle. $\mathrm{O}$ controle dá-se em céu aberto, sem espaço estriado. E o que a educação para a multidão poderia propor em relação aos processos de subjetivação na direção de um "povo que falta", um povo que precisa ser inventado (Deleuze, 1992)?

Insistimos na urgência de discutir a maneira pela qual as pedagogias e os pedagogos da infância estão no interior da construção do povo. Mais urgente, ainda, para nós, é propor possibilidades de escapar dessa lógica, valendo-nos da idéia da infância como experiência, tal como presente em Benjamin (1987) e Agamben (2005), bem como das pedagogias da infância para oferecer uma educação como prática da diferença. 


\section{Pedagogias suplicantes, pedagogias prescritivas}

Segunda cena: Criança de 4 anos sozinha na classe. Professora inquieta-se ao ver a criança pequena em silêncio, quieta, observando o restante da turma, que brinca no parquinho. Tenta convencê-la a brincar e a juntar-se ao grupo.

A concepção de criança nessa cena é a de um ser eminentemente gregário. Sobre gregarismo, há uma infinidade de definiçôes que remetem à característica de coletivo, de bando. Similarmente, na ecologia, na educação e na psicologia social, apenas para mencionar algumas áreas de problematização, tem-se o subsídio da biologia evolutiva de Darwin: por conta da reprodução, a seleção entre seres orgânicos dar-se-ia naturalmente para a propagação e perpetuação da espécie ${ }^{10}$.

Com o propósito de promover desenvolvimento e socialização, as iniciativas pedagógicas calcadas no gregarismo assujeitam e subjetivam a criança pela uniformização de seus desejos, pela pasteurização de suas singularidades, pelo apassivamento de seus talentos e pela desautorização de seu discurso. Produzir diferenças torna-se, portanto, um desafio para as práticas educacionais, uma vez que delas se exige um posicionamento teórico diferente, talvez um desmantelamento do que foi produzido como referenciais em educação, referendados pela cultura, pela idéia de povo e pelas áreas que a formam, a exemplo da psicologia, com forte influência na educação. Os modelos experimentados, quando não reverteram em fracasso, resultaram em descrédito da sociedade em relação à educação, vista como depositária fiel da cultura. Com efeito, podemos ir além do inventariar histórias, índices, estatísticas e anedotas de fracasso escolar.

10. Tem-se gregarismo como: I) grupo de indivíduos que se agregam para desenvolver uma parte do seu ciclo biológico juntos (Instituto de Estudos Sócio-Ambientais do Sul da Bahia - IESB); 2) tendência dos animais a viver agrupados em rebanhos ou manadas, sem que esse agrupamento tenha um sentido social. Aplica-se o qualificativo gregário aos seres humanos que estão em companhia de outros, sem estabelecer entre si nem comunicação nem regras de empatia. Também se diz do indivíduo que segue servilmente as idéias ou iniciativas alheias, deixando-se conduzir como se estivesse num rebanho. (www.edu.xunta.es); 3) instinto gregário, ou o quarto instinto (a autopreservação, a nutrição e o sexo seriam os três primeiros). O gregarismo, segundo W. Trotter, justifica-se "em termos darwinistas como uma espécie de aquisição pela qual os organismos complexos tornar-se-iam mais resistentes ao rigor da seleção natural. A explicação de tal hipótese seria fundada na suposição de que a variabilidade das unidades (células) teria, através da união e da extensão pluricelular, um limite mais largo, de maneira que os riscos corridos por cada uma, em relação ao ambiente, não comprometeriam o organismo como um todo. O gregarismo seria uma espécie de qualidade fundamental no homem que teria repercussões em sua estrutura mental." (Trotter apud Mello Neto, 2000, p. I47). 
Tornar uma criança um ser sociável está presente em várias propostas pedagógicas e psicopedagógicas, cada uma, a seu modo, trazendo de roldão uma concepção de criança para um povo, para uma nação. A criança sociável sempre esteve presente na história da educação e em todas as matrizes educativas, é ela que deve ser produzida a partir da mecânica pedagógica.

Se uma criança pequena se isola do grupo, isso pouco ou nada diferiria do monólogo coletivo preconizado por Piaget. Segundo ele, nesse estágio, brincar junto é brincar cada qual com seu brinquedo, mas a uma distância tal que olhares possam cruzar-se, sons possam ser compartilhados, sombras de uns projetem-se em outros, etc. São atos infantis que não carregam características subjetivas, apenas particularidades. Empurrar a criança para a socialização é dar-lhe o formato de cidadão, o direito de viver entre os pares e de ter sua proteção assegurada. A escola, assim como a família, a igreja, o quartel, o hospital, acolhem, amparam na mesma medida que corrigem e moldam os desviantes potenciais. $\mathrm{O}$ aparelho disciplinar dociliza e produz o corpo, constrói-lhe novo mobiliário, cria paladares, recorta o tempo, esquadrinha o deslocamento, define papéis, e vigia. ${ }^{11}$

Freinet e Wallon, iniciados no movimento da Escola Nova francesa no início do século XX - e posteriormente dela dissidentes -, acrescentaram moldura política à motivação intrapsíquica que comandava a gênese piagetiana do conhecimento. Cabe menos analisar se o primeiro tendeu para um projeto comunista "bucólico" e o segundo para a crítica ao rousseaunismo da visão escola-novista (criança = bom selvagem, daí laisser faire, laisser passer). $\mathrm{O}$ importante é lembrar que o engajamento político é a marca dos projetos em educação de Freinet e de Wallon. A espinha dorsal seria a concepção iluminista de homem, em que a razão aparece como alicerce para a tríade igualdade-fraternidadeliberdade. O caráter romântico presente na idéia de um homem naturalmente bom, baseado em Rousseau (considerado um dos percursores do romantismo), por sua vez, nega a razão como propulsora desses princípios, por acreditar ser ela o que retira do homem sua vitalidade, sua intuição, sua fantasia. Daí a necessidade de forjar uma educação que tenha na Natureza seu objeto e seu objetivo (Giles, 1983, p. 76-77).

Cabe acentuar que tanto o modelo de Freinet quanto o de Wallon atualizaram a idéia de Vygotsky de incutir na educação um projeto de nação. Freinet e Wallon foram além, ao defender, cada um a seu estilo, que uma nação igualitá-

11. Sobre mecanismos disciplinares e adestramento ver: Foucault, 1977, p. I53-159. O mesmo autor propõe na Aula de 17 de março de 1976 (aulas compiladas na obra Em defesa da sociedade), no Collège de France, o esgarçamento do sentido de disciplina, retirando-a dos limites do corpo individual e diluindo-a numa tecnologia de poder massificante, isto é, voltada não apenas para o homem-corpo, mas para o homem-espécie (idem, 1999, p. 288-289).

Pro-Posições, Campinas, v. 20, n. 3 (60), p. 179-197, set./dez. 2009 
ria, isonômica, de apoio integral à criança, deveria levar em conta, paralelamente ao projeto político, as várias instâncias do desenvolvimento infantil: saúde mental e física, com atenção às deficiências motoras, cognitivas, emocionais; incentivo aos talentos; e orientação às vocações. Freinet, no período entre as duas grandes guerras mundiais, propôs uma educação que acontecesse a partir da força vital do indivíduo. Defendia uma intervenção mínima da figura do professor. No seu entender, o adulto deveria apoiar as descobertas da criança que, tateando a natureza, vivenciando experiências, tornava-se capaz de elaborar seus critérios de aprendizagem, agindo, inclusive, no registro de suas descobertas e na própria escolha dos conteúdos. ${ }^{12}$

Wallon, a serviço do Ministério da Educação Nacional francês, elaborou um projeto de reforma da educação para o período após Segunda Guerra Mundial. Em 1946, como responsável pela redação final do projeto, Wallon defendeu a proposta de promover uma educação pública, laica, gratuita, firmada no princípio da justiça social. Com base no que chamava de psicogênese da pessoa completa, reivindicava um modelo que desse conta, de maneira integrada, dos aspectos emocionais, motores, intelectuais e vocacionais das crianças. ${ }^{13}$

Ambos foram além, ao defenderem, cada um a seu estilo, que uma nação igualitária, isonômica, de apoio integral à criança, deveria levar em conta, paralelamente ao projeto político, as várias instâncias do desenvolvimento infantil: saúde mental e física com atenção às deficiências motoras, cognitivas, emocionais, incentivo aos talentos e orientação às vocações.

Vygotsky, que não desvencilhou o processo de ensino-aprendizagem da construção do novo estado soviético que ajudara a inaugurar, postulou para esse processo a figura do mediador, podendo ser esse um sujeito, um objeto, uma idéia, uma lembrança, etc. Entendendo o materialismo dialético de Marx e Engels como fundante na obra de Vygotsky, tem-se também a noção de educação assemelhada à noção de trabalho, ou seja, algo que transforma a natureza pressupooe a criação de ferramentas e não se dá sem interação. É, portanto, o contexto sócio-histórico que transforma os processos mais elementares de desenvolvimento biológico do homem nas chamadas funções psíquicas superiores (Rego, 1999, p. 100).

12. Em Ensaios de Psicologia sensível. São Paulo: Martins Fontes, 1998, p. 18 e seguintes, Freinet lança mão de metáforas da botânica, oferecendo exemplos de formulações que apontam para o vitalismo.

13. Cf. Isabel Galvão para as críticas de Wallon quanto ao individualismo marcante na Escola Nova; quanto à pouca ênfase dada à inteligência em detrimento do instinto e do primitivo na educação sob regimes fascistas e, também, quanto ao elitismo do sistema educacional francês. Henri Wallon. Uma concepção dialética do desenvolvimento infantil. 10a . Edição. Petrópolis: Vozes, 2002, pp. 93-95. 
De qualquer forma, a figura do mediador serviu para a convicção de Vygotsky de que não era possível desenvolver conhecimento de forma individualista e competitiva. Exemplo disso era a defesa de que a linguagem precederia o pensamento. Daí o caráter interacionista da aprendizagem. Em outras palavras, seriam as vivências societárias que levariam a criança a adquirir as funções intelectuais. Estas dependeriam "de seu domínio dos meios sociais do pensamento, isto é, da linguagem" (Vygotsky, 1991, p. 44). A passagem do nível de desenvolvimento real (o que o indivíduo já sabe por si) para o nível de desenvolvimento potencial (o que o indivíduo é capaz de aprender com o auxílio do mediador), em certa medida, assemelha-se à passagem do senso comum ao bom senso. Isso porque na filosofia política marxista, seja por meio de Gramsci, seja pelo próprio Lênin, a ascensão de um estado de compreensão a outro, ou a passagem do senso comum ao bom senso, dá-se pela intervenção de intelectuais orgânicos ${ }^{14}$, em uma vertente; ou, pelo partido político, em outra, os quais novamente têm função mediadora.

$\mathrm{O}$ que temos nas várias abordagens pedagógicas e nas ações que lhes servem de corolário é uma subalternização de relações em nome de um contrato social em que o indivíduo é educado para um lugar definido na sociedade, seja o de opressor, seja o de oprimido, reacionário ou revolucionário, alienado ou socialmente consciente, etc. Ser diferente, nessa perspectiva, dá ao indivíduo uma nuance patológica. A criança que se isola do grupo passa a ser um aluno preocupante: há que fazê-la brincar com os outros! Há que brincar, pois é uma estratégia importante para a construção da criança coletiva, que fará parte da nação e do povo em construção. Brincar, nessa concepção, é a atividade socializadora, por excelência, e necessariamente intencional na construção do povo que virá. O novo mundo, preconizado por toda a educação, já está embutido nas pedagogias e nada tem a ver com a possibilidade de incorporar idéias que as novas geraçôes trazem.

Se transpusermos para a educação infantil as premissas de Deleuze e Guattari de um pensar diferente sobre o sujeito, poderemos vislumbrar maior potência para a diferença. Estar no grupo sem estar com o grupo, fato corriqueiro no brincar infantil, constitui uma hecceidade, isto é, um comportamento que envolve "individuações sem sujeito" (1995, p. 8), como aquele observado entre as crianças pequenas que repetem de modo singular as expressões, os trejeitos, os olhares e os sorrisos de suas coetâneas. Isso joga outra luz sobre o monólogo coletivo de Piaget, já que o libera de seu quantum individualizante, supondo a quebra da dicotomia uno e múltiplo e instituindo em seu lugar as multiplicidades compostas de singularidades, hecceidades e devires.

14. Para definições de pressupostos gramscianos, cf. BOCAYUVA, Pedro Cláudio Cunha; MAYRINK VEIGA, Sandra. Novo vocabulário político, Rio de Janeiro: FASE; Petrópolis: Vozes, I992. v. I. 
Os devires são processos, tempos de entendimento que envolvem dois sujeitos, um sujeito e um objeto, ou, ainda, dois objetos. Devir entendido como movimento, processualidade, trajetos, forças intensivas ${ }^{15}$. Não se trata de identificação entre as partes ou redução, menos ainda da transformação de uma na outra. É um momento que envolve afectibilidade, isto é, poder de afetar ou ser afetado. Pensar, devir e afectibilidade mostrar-nos-iam outra possibilidade ao remetermo-nos à díade professora-aluna da cena proposta anteriormente: o que moveria a professora não seria a piedade (em ver uma criança só), nem a identificação (ser menina, ser sozinha, a criança da sua infância, a criança que poderia ter sido...), nem a simbiose (eu faço por você para fazer para mim). Poderia vir a ser uma composição de velocidades e afetos entre indivíduos inteiramente diferentes. A professora perceberia ali uma singularidade como expressão das multiplicidades que estão sendo vivenciadas, na realidade, por ambas.

Há, então, o embate entre o bloco da cultura (ou bloco histórico, se pudermos lembrar Gramsci) e o bloco de devires: a pontualidade dos fatos versus o processo ou o movimento dos afetos; a diferença entre algo que é posto e algo que nem é posto, nem é tornar-se, nem se identificar. Questionar a cultura exige, portanto, a extrapolação da ordem binária, que explica o mundo pelas oposições consciente-inconsciente, voz-escrita, história-natureza, masculinofeminino, corpo-alma, que têm marcado tanto o racional quanto o imaginário ocidental. O importante seria romper com o maniqueísmo atávico dessas dicotomias para ver a potência de algo novo, mais libertário e quem sabe "mais saudável" - em oposição à saúde dominante que elegeu determinadas concepções de força física, beleza, cor e sexualidade como padrão de saúde -, tanto para o indivíduo quanto para as relações que quisesse estabelecer.

15. Sobre devir, entre outros trechos, há: "Os devires são geografias, são orientações, direções, entradas, saídas. Há um devir-mulher que não se confunde com as mulheres, com seu passado e seu futuro, e é preciso que as mulheres entrem nesse devir para sair do seu passado e de seu futuro, de sua história. Há um devir revolucionário que não é a mesma coisa que o futuro da revolução, e que não passa inevitavelmente pelos militantes... Devir é jamais imitar, nem fazer como, nem ajustar-se a um modelo, seja ele de justiça ou de verdade. Não há um termo de onde se parte, nem um ao qual se chega ou se deve chegar. Tampouco dois termos que se trocam. A questão 'o que você está se tornando'? é particularmente estúpida. Pois à medida que alguém se torna, o que ele se torna muda tanto quanto ele próprio." (Deleuze; Parnet, 1998, p. 10). "Devir não é atingir uma forma (identificação, imitação, mimese), mas encontrar a zona de vizinhança, de indiscernibilidade ou de indiferenciação tal que não seja possível distinguir-se de uma mulher, de um animal, de uma molécula: não imprecisos nem gerais, mas imprevistos, não-preexistentes, tanto menos determinados numa forma quanto se singularizam numa população... O devir está 'entre'ou 'no meio': mulher entre as mulheres, ou animal no meio dos outros." (Deleuze, 1997, p. 9). "Mas uma linha de devir não tem nem começo nem fim, nem saída nem chegada, nem origem nem destino; e falar de ausência de origem, erigir a ausência de origem em origem, é um mau jogo de palavras. Uma linha de devir só tem meio. O meio não é uma média, é um acelerado, é a velocidade absoluta do movimento." (Deleuze; Guattari, 1997, p. 91). 
Voltando à proposta deleuziana, lembramos que o devir tem mais de alianças que de rupturas, de modo que a professora dessa cena não se torna criança nem a criança se torna outra coisa. Relações de afectibilidade são compostas de movimento e repouso, velocidade e lentidão, e propiciam um grau de potência de ação (Deleuze; Guattari, 1995, p. 42). É dessa potência que se pode pensar em produzir diferença.

Voltando às cenas aqui propostas, vemos que a ação pedagógica projetada se insere na ordem da cultura e engendra práticas sociais coercitivas, nega a solidão (da criança, do louco, do poeta), recolhe a vida, a memória das minorias ${ }^{16}$ em movência, destituídas, portanto, de status institucional, para dar-lhes outra configuração. Produz, ainda, valores que consolidam o ideário hegemônico por meio do hipercontrole exercido pelas agências micropolíticas.

Não é que os professores tenham matado ou deixado morrer a utopia iluminista/racionalista que serviu de berço à educação. É que, em tempos pósmodernos, há uma falência de modelos ou mesmo de referências que possam atender às novas configurações de tempo e espaço, tanto do social quanto do econômico, que surgem a todo momento no contexto das múltiplas identidades. As grandes narrativas não bastam para explicar o futuro humano, mesmo porque tal futuro está cada vez mais imediato, dada a plasticidade do capital muito bem aconchegado pelo desejo de um Estado mínimo, pelas tecnologias e pelas simulaçōes (Libâneo, 2002, p. 174-178), pelas identidades que emergem cada vez mais rapidamente, exigindo quebra de consenso. Em paralelo à teia do mercado, surgem as redes de solidariedade, cuja potência resvala mais que em uma alternativa econômica, porque elas não idealizam o shopping center, como o faz o bazar; tampouco aspiram à excelência empresarial, como o faz a cooperativa. A proposta é de uma outra estética, outro laço que só surge em cenário multitudinal regido por multiplicidades, itinerâncias e nomadismo.

E se o ambiente mudou, se o futuro está aí desde ontem, se muitos de nós se incomodam dentro do modelito "cyber-zumbi" (Pelbart, 2000, p. 23), como pensar uma nova educação?

\section{Infância e experiência}

Criança e infância são conceitos que têm sido configurados como unívocos. Juridicamente, com base também nas ciências biológicas, considera-se criança

16. "É primeiro porque o homem é majoritário por excelência, enquanto que os devires são minoritários, todo o devir é um devir minoritário. Por maioria nós não entendemos uma quantidade relativa maior, mas a determinação de um estado ou padrão em relação ao qual tanto as quantidades maiores quanto as menores serão ditas minoritárias: homem-branco, adulto-macho, etc. Maioria supõe um estado de dominação, não o inverso." (Deleuze; Guattari, 1997, p. 87). 
toda a pessoa na faixa etária entre 0 e 12 anos. Já a infância tem sido construída como um bolsão de sentidos que se sobrepõe a todas as crianças. Trata-se, então, de um conjunto de sentidos normativos que, de maneira geral, prescrevem o seu brincar, o seu tempo, a sua sociabilidade, a estética, a higiene, os hábitos, etc. e enfatizam o caráter disciplinar do que é ser criança. Nesse sentido, infância guarda relação com povo. Como numa prescrição, revela uma concepção de criança que pressupõe determinada infância para desabrochar no adulto. $\mathrm{O}$ foco é o adulto. A criança e sua infância prescrita são um interregno. Dessa forma, é vista como aquela que tem ou não infância. A criança é educada no interior do que é ter uma infância, mas na direção de tornar-se um adulto.

O que sabemos, entretanto, é que criança é um intervalo populacional que abarca todas as crianças. Há bilhóes delas, de todos os jeitos e em toda a parte, vivendo diversas infâncias, em diversos tempos. Criança e infância são, portanto, múltiplas e, dessa maneira, guardam relação com a multidão, em virtude de seu caráter muitas vezes nômade, intempestivo e selvagem, que faz tudo fugir.

Ainda que a idéia de infância tenha servido, paradoxalmente, como escudo contra um mundo adulto inserido na lógica do capital que produz sua morte, já que a história da criança é a história da violência, do espancamento, da fome, da invisibilidade, da desqualificação, é preciso que se pense numa educação para a multidão, para que se faça, de fato, uma educação para a criança, levando em conta suas multiplicidades, itinerâncias, singularidades. A infância deveria, de alguma maneira, recuperar a multidão com a qual se identifica, isto é, antes de ser refém do povo.

Como criar e produzir um espaço fora das amarras de sentido, da idéia de infância/povo, uma espécie de espaço fora-da-infância, uma banda larga, uma margem maior, que nunca se sabe exatamente aonde se vai chegar, em que as crianças possam ficar sós, pensar, grunhir, falar, etc.?

Se se quer produzir diferença é porque ela está ali e precisa fazer valer sua potência política, precisa ser tirada do lugar do estranho, do horrível e da aberração. Mas isso num movimento não de conversão em lucro para o capital, que tem sido hábil em lhes retirar o que têm de único e talvez último, que são sua potência e sua vida. A diferença precisa ser retirada da cena onde foi satanizada para ser recolocada na multidão, onde a paisagem é indefinida, onde não se sabe exatamente quem é quem e o que é o que, mesmo porque ela é nômade: quem estava ali não está mais, quem chegou já saiu.

A educação de crianças pequenas coloca-as no espaço público, que deveria ser um espaço não fraternal, não doméstico e nem familiar. Queremos dizer com isso que o espaço público é aquele que permite múltiplas experimentações. É o espaço, por excelência, da criação, em que se exercitam formas dife- 
rentes de sociabilidade, subjetividade e ação, o que não é possível em espaços familiares, que priorizam a segurança material e imaterial. $\mathrm{O}$ espaço público expõe e possibilita à criança outros agenciamentos, afetos e amizades. É preciso saber aproveitar as possibilidades de acontecimentos que se inauguram na cena pública e escolar. A professora não é a mãe, nem a tia; a colega não é a irmã; e brincar de casinha não é imitar papai-e-mamãe, bem como as histórias infantis não precisam remeter a um final feliz e nem à idéia de mulher, de casal e de povo. Nessa educação, a professora está fortemente empenhada em entender o que as crianças falam, o que querem conhecer, o que há de interessante a fazer e a deixar de fazer, a estudar, deixar para lá; pensar o que há de interessante para visitar, que novas formas de brincar podem ser brincadas, que músicas e que danças podem ser inventadas. Talvez valha a pena aproveitar a idéia das cem linguagens ${ }^{17}$ preconizada pela escola italiana no interior de uma educação com a criança, no espaço público, em que as afectibilidades criem novas redes de solidariedade e pensamento para que se possibilite um devir-criança.

Giorgio Agamben, particularmente na obra Infância e história,

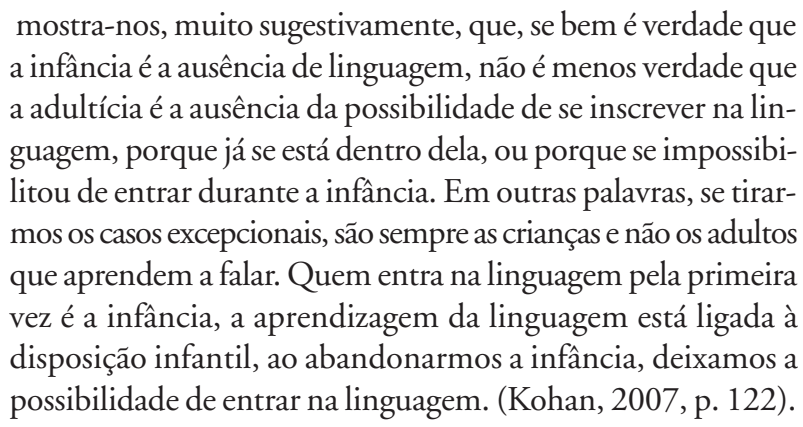

A partir dessa vertente, há um esforço teórico para pensar a infância em suas positividades, naquilo que ela já é, nas suas capacidades, singularidades e potências - nos devires - e não como uma fase ou etapa passageira, seja de desenvolvimento ou comportamento, nem mesmo pensá-la como aquilo que será, um vir-a-ser adulto. Para Agamben, a infância não deve ser compreendida como:

algo que precede cronologicamente a linguagem e que, a uma certa altura, cessa de existir para versar-se na palavra, não é um paraíso que, em um determinado momento, abandonamos para sempre a fim de falar, mas coexiste originalmente com a linguagem, constitui-se, aliás, ela mesma na expropriação que dela

17. Vejamos, então, um trecho do poema "Ao contrário, as cem existem", de Loris Malaguzzi: "A criança / é feita de cem. / A criança tem cem mãos / cem pensamentos / cem modos de pensar..." (Loris Malaguzzi, 2004). 
efetua, produzindo a cada vez o homem como sujeito. (Agamben, 2005, p. 59).

Nesse sentido, ao aproximar a idéia de infância ao conceito de experiência, há a construção de subjetividades, faz-se a saída da condição de in-fante (não falante) à condição de falante, transforma-se língua em discurso, insere-se numa cultura e abre-se para a construção de outras culturas e outras linguagens.

Para terminar, gostaríamos de retomar e aproveitar a idéia da infância como experiência, devolvendo ao conceito uma multiplicidade que lhe foi retirada pelas pedagogias que o colocaram como refém do povo. A idéia da infância carrega possibilidades de acontecimento, inusitado, diruptivo, escape que nos interessa para pensar a diferença. O que se quer dizer é que a experiência da infância não está vinculada unicamente à idade, à cronologia, a uma etapa psicológica ou a uma temporalidade linear, cumulativa e gradativa, já que ligada ao acontecimento; vincula-se à arte, à inventividade, ao intempestivo, ao ocasional, vinculando-se, portanto, a uma des-idade. Dessa forma, como experiência, pode também atravessar, ou não, os adultos. Há pessoas que são mais ou menos atravessadas por ela. É a infância que pode vir a propiciar os devires enunciados neste artigo. Devir não como um vir-a-ser, pois já vimos que nada tem a ver com futuro, com uma cronologia qualquer, mas, sim, com aquilo que somos capazes de produzir e de inventar como possibilidade de vida, potência de vida, o poder da vida opondo-se ao poder sobre a vida. Pois o espaço da criação também deve ser produzido, numa espécie de produção de produção do espaço de criar.

A infância pode ser uma forma de opor-se ao poder sobre a vida. A infância em suas experimentaçóes efetua-se, acontece em um tempo mais generoso, por ser mais estendido, mais largo, já que é um tempo vinculado ao acontecimento, à criação. Um tempo que não se submete ao tempo imposto pelo poder e pelo capital. Já que é disso que se trata, como já vimos, o poder e o capital impóem um funcionamento ao corpo e à vida, subjetivando e submetendo todos no interior de uma mesma lógica. A escola de Educação Infantil tem como função prioritária promover as infâncias, já que nem todos as têm. Desse modo, há de se inventar estratégias educacionais promotoras de infâncias e de devir(es), modelos de diferenciação, para que todas possam diferir e experimentar. O desafio posto para o professor de Educação Infantil é propor uma educação cujas práticas educativas não impeçam o devir, mas o implementem. Portanto, o desafio é o de implementar o exercício da infância. 


\section{Referências bibliográficas}

ABRAMOWICZ, Anete. Educação infantil e a escola fundamental de 9 anos. Olhar de Professor, Ponta Grossa, v. 9, n. 2, p. 317-325, 2006.

ABRAMOWICZ, Anete; RODRIGUES, Tatiane; CRUZ, Ana. Fracasso escolar na sociedade de controle e Aprendi o que é ser preto sob o racismo da escola. In: ARROYO, Miguel; ABRAMOWICZ, Anete (Org.). A reconfiguração da escola: entre a negação e a afirmação dos direitos. Campinas: Papirus, 2009.

AGAMBEN, Giorgio. Infância e história - destruição da experiência e origem. Tradução de Henrique Burigo. Belo Horizonte: Ed. UFMG, 2005. (Coleção humanitas).

BENJAMIN, Walter. Magia e técnica, arte e política - ensaios sobre literatura e história da cultura. In: BENJAMIN, Walter. Obras Escolhidas. Tradução de Sergio Paulo Rouanet. São Paulo: Brasiliense, 1987.v. 1.

BOCAYUVA, Pedro Cláudio Cunha; MAYRINK VEIGA, Sandra. Novo vocabulário político. Rio de Janeiro: FASE; Petrópolis: Vozes, 1992. v. 1.

DELEUZE, G. Mil platôs. Capitalismo e esquizofrenia. Rio de Janeiro: Editora 34, 1994. v. 4.

DELEUZE, G. Conversaçôes: 1972-1990. Rio de Janeiro: Editora 34, 1992.

DELEUZE, Gilles ; GUATTARI, Félix. Milplatôs. Capitalismo e esquizofrenia. Rio de Janeiro: Editora 34, 1995. v. 1.

DELEUZE, Gilles; PARNET, Claire. Diálogos. São Paulo: Escuta, 1998.

ENGELS, Friederich. Do socialismo utópico ao socialismo científico. São Paulo: Global. Publicado originalmente em 1877.

FOUCAULT, Michel. Vigiar e punir. Nascimento da prisão. Petrópolis: Vozes, 1977.

FOUCAULT, Michel. Microfísica do poder. 4. ed. Rio de Janeiro: Graal, 1984.

FOUCAULT, Michel. Em defesa da sociedade. São Paulo: Martins Fontes, 1999.

FREINET, Célestin. Ensaios de psicologia sensivel. São Paulo: Martins Fontes, 1998.

GALVÃO, Izabel. Henri Wallon. Uma concepção dialética do desenvolvimento infantil. 10. ed. Petrópolis: Vozes, 2002.

GARIBOLDI, Antonio. O dia-a-dia educativo em uma pré-escola. In: BECCHI, Egle; BONDIOLI, Anna (Org.). Avaliando a pré-escola: uma trajetória de formação de professoras. Campinas, SP: Autores Associados, 2003.

GILES, Thomas Ransom. Filosofia da educação. São Paulo: E.P.U., 1983.

HARDT, Michael; NEGRI, Antonio. Império. Tradução de Berilo Vargas. 3. ed. Rio de Janeiro/ São Paulo: Record, 2001.

HARDT, Michael; NEGRI, Antonio. Multidão: guerra e democracia na era do Império. Rio de Janeiro/São Paulo: Record, 2005. HASENBALG, Carlos. Discriminação e desigualdades raciais 
no Brasil. 2. ed. Belo Horizonte: Ed. UFMG, 2005 (Coleção humanitas).

KOHAN, Walter O. Infância, estrangeiridade e ignorância: ensaios de filosofia e educação. Belo Horizonte: Autêntica, 2007.

LIBÂNEO, José Carlos. Pedagogia e pedagogos, para quê? São Paulo: Cortez, 2002.

LORIS, Malaguzzi. Ao contrário, as cem existem. Revista Bambini, Bergamo, ano 10, n. 2, fev. 2004. Tradução livre do original italiano de: Ana Lúcia Goulart de Faria, Maria Carmem Barbosa e Patrizia Piozzi.

MELLO NETO, Gustavo Adolfo Ramos. A psicologia social nos tempos de S. Freud. Psicologia: Teoria e Pesquisa, Brasília, v. 16, n. 2, 2000.

PELBART, Peter Pál. Vida capital: ensaios de biopolítica. São Paulo: Iluminuras, 2003.

REGO, Teresa Cristina. Vygotsky. 7. ed. Petrópolis: Vozes, 1999.

VIRNO, Paolo. Gramática multidão: para uma análise das formas de vida contemporâneas. Tradução de Leonardo Retamoso Palma, 2003. Mimeo.

VYGOTSKY, Lev. Pensamento e linguagem. São Paulo: Martins Fontes, 1991.

Recebido em 10 de outubro de 2008 e aprovado em 18 de setembro de 2009. 